\title{
Study on Preparation and Performance of High Swelling Bentonite
}

\author{
Shuangchun Yang ${ }^{1,2}$, Mingzhe Guo ${ }^{2}$, Erlong Yang ${ }^{1}$, Haiyan Zhang ${ }^{3}$
}

\author{
${ }^{1}$ School of Petroleum Engineering, Northeast Petroleum University, Daqing, Heilongjiang, China. \\ ${ }^{2}$ College of Petroleum Engineering, Liaoning Shihua University, Fushun, Liaoning, China. \\ e-mail: yangchun_bj@126.com \\ ${ }^{3}$ Key Laboratory of petroleum and natural gas resources, Qinzhou University, Qinzhou, Guangxi, China. \\ e-mail: gmz_1sh@126.com, panhongxiang@126.com,gmz_hte@126.com
}

\begin{abstract}
For improving the expansibility of natural $\mathrm{Ca}$-based bentonite (Ca-Bent), the Ca-Bent was modified with sodium dodecyl benzene sulfonate(SDBS) $-\mathrm{Na}_{2} \mathrm{CO}_{3}$ complex agent by microwave semi-dry method. And the ratio of $\mathrm{Na}_{2} \mathrm{CO}_{3}$ to SDBS, microwave power, radiation time and initial temperature on the modification were studied. Furthermore, X-ray diffraction (XRD) patterns and infra-red spectrum (IR) were carried out to characterize, which obtain microstructure of samples. The result showed that the optimized experimental parameters are obtained as follows: $\mathrm{Na}_{2} \mathrm{CO}_{3}$ to SDBS ratio 1:1, radiation time $2 \mathrm{~min}$, microwave power $600 \mathrm{~W}$ and initial temperature $120 \mathrm{~K}$. Besides, under the optimization conditions, the modified bentonite has swelling volume of $68.5 \mathrm{~mL} / \mathrm{g}$, cation exchange capacity of $56.2 \mathrm{mmol} / 10^{2} \mathrm{~g}$ and yield point and plastic viscosity ratio of 1.67, respectively. A comparison of the single factor experiment and orthogonal experiment indicates that the SDBS and $\mathrm{Na}_{2} \mathrm{CO}_{3}$ have synergistic effect in the process of modification, especially, under the optimum microwave condition, $\mathrm{Na}_{2} \mathrm{CO}_{3}$ increased the anion activity of SDBS, which enhanced the hydrophilicity of modified bentonite. The experimental result show that the process improves the swelling volume of bentonite and the comprehensive performance. So, the modified bentonite was a perfect additive in water drilling mud.
\end{abstract}

Keywords: Ca-Bent, SDBS- $\mathrm{Na}_{2} \mathrm{CO}_{3}$ complex agent, high swelling.

\section{INTRODUCTION}

Bentonite is a non-metallic mineral, montmorillonite $\left((\mathrm{Na}, \mathrm{Ca})_{0.3}(\mathrm{Al}, \mathrm{Mg})_{2} \mathrm{Si}_{4} \mathrm{O}_{16}(\mathrm{OH})_{2} \_\mathrm{xH}_{2} \mathrm{O}\right)$ as the main mineral component, and a sandwich structure composed of silicon oxygen tetrahedron and alumina eight surface, monoclinic. Because of this special layered structure, it has a large specific surface area, so it has strong adsorption. Bentonite has strong hygroscopicity and expansibility, and it can absorb 8 15 times the volume of water. Bentonite is a colloidal and suspended in aqueous solution, the suspension has viscosity, thixotropy and lubricity, especially, there is strong ion exchange capacity and adsorption capacity for gas, liquid and organic matte.[1]

The natural bentonite is divided into two types: Ca-based bentonite(Ca-Bent) and Na-based bentonite(Na-Bent). There are abundant resources of bentonite in the world, but the distribution is not balanced, bentonite resources are mainly distributed in the Pacific Rim belt, India ocean belt and Mediterranean Sea-Black Sea belt. China, the United States, the Commonwealth of Independent States, Germany, Italy, France, Japan and Greece is the main resource country. Although the reserves of bentonite in the world are large, more than $70 \%$ bentonite is inferior Ca-Bent. However, the Ca-Bent is limited to be used in divese fileds, the natural Ca-Bent is modified because Na-Bent takes on high properties of water swelling, so it have extensive applications in the different industrial fields such as ceramic, paints, food, drug manufacturing, treating polluted water, such as the adsorption of toxic organic compounds and stabilization of oil-water emulsions. The NaBent dispersions are widely used in industrial processes because of their exceptional colloidal and rheological properties. [2]

The physical and chemical properties of Ca-based bentonite are mainly characterized by good adsorbability and cohesiveness, but little swelling. Sodium bentonite or organic bentonite shows excellent swelling and colloidal properties. Due to the structural of bentonite, $\mathrm{Ca}^{+}$of bentonite layers can be exchanged to other cations, which achieve the purpose of modification.

Huang et al.[3] studied the Ca-based bentonite was modified by $\mathrm{Na}_{2} \mathrm{CO}_{3}$, which in order to improve per- 
formance of metallurgical pellet bentonite. Kumararaja et al. [4] studied bentonite clay was pillared with polyhydroxy aluminum complexes, and pillared bentonite could potentially be used for solving heavy metal pollutions by immobilising the metals in the contaminated soil. Zhou et al. [5] presented a method that groundwater was filtered with mixtures of sodium bentonite and clay, the result showed excellent adsorption effect for ammonium and phosphate was attributed to the addition of sodium bentonite. Ahmed S. Mohamed[6] discovered that iron oxide nanoparticles $\left(\operatorname{nanoFe}_{2} \mathrm{O}_{3}\right)$ modified bentonite, the modified bentonite improved rheological properties of drilling mud. Lisi et al[7] studied the talc was modified with surface active agent by microwave, it's found that the microwave modified silicate minerals was better. However, most of the bentonite was modified by inorganic sodium salt or sodium modification after organic. And anionic surfactant and inorganic salt composite modified natural Ca-Bent wasn't reported. So in order to modify Ca-Bent effectively, modification experiment of Ca-Bent was carried out with $\mathrm{SDBS}-\mathrm{Na}_{2} \mathrm{CO}_{3}$ complex agent by microwave semi-dry method.

\section{MATERIALS AND METHODS}

\subsection{Materials and Equipments}

The following materials and instruments were used for the experiments: bentonite (325mesh) for preparing the modified bentonite was supplied by Lingshou County Xing Yuan mineral powder processing plant (Hebei, China); sodium carbonate, sodium dodecyl benzene sulfonate and absolute ethanol (analytical reagent) from Sinopharm Chemical Reagent Co, Ltd. (Shanghai, China) were used in this study. Na-based bentonite was used to prepare drilling fluid from PetroChina Liaohe Oilfield Company (Liaoning, China).

The equipment included MAS- IIPLUS type microwave synthesis/extraction reaction workstation(Shanghai Xinyi Microwave Chemical Technology Co., Ltd.), PHSJ-5 laboratory $p H$ meter(Shanghai Jinpeng Analysis Instrument Co., Ltd.), ZNN-D6B electronic six speed rotary viscometer(Qingdao Hongxiang Petroleum Machinery Manufacturing Co., Ltd.), 78-1 magnetic heating stirrer(Jintan Jiangsu Hengfeng Manufacturing Co., Ltd.), FTIR-660+610 Fourier transform infrared spectrometer (Agilent Technologies) and D8 Advance X ray diffractometer (Brukcr, Germany).

\subsection{Pretreatment of calcium bentonite}

The calcium bentonite samples were treated before using in the experiments as follows. 325 mesh sizes of calcium bentonite were mixed with $300 \mathrm{~mL}$ distilled water, and the mixtures were stirred for $1 \mathrm{~h}$. After stirring, all mixtures were stood for $1 \mathrm{~h}$ and the small impurities suspended in the supernatant were removed with a pipette. This process was repeated until the supernatant was clear. The resulting products were then dried at $221 \mathrm{~K}$.

\subsection{Modification.}

First, SDBS and $\mathrm{Na}_{2} \mathrm{CO}_{3}$ were mixed in different proportions, and mixtures of $\mathrm{Na}_{2} \mathrm{CO}_{3}$ and SDBS dissolved in 50\% ethanol, we obtained required modified agent. The $5 \mathrm{~g} \mathrm{Ca}$-based bentonite was mixed with the modifying agent, which was the semi-dry reaction material. The mixture is placed evenly on bottom of flask, and keep still for 30 minutes before microwave treatment. Then, the flask with the reaction material was put into microwave apparatus and different parameter of microwave was set. The parameters of microwave included time, initial temperature and microwave power. In particular, the electromagnetic stirring speed should be controlled at 500r/min. After the reaction material was placed in digital display blast drying box and dried at 176K.Finally, the reaction material was ground and sieved so that 140 mesh powder were obtained.

According to the order of $\mathrm{Na}^{+}, \mathrm{K}^{+}, \mathrm{Mg}^{2+}$ and $\mathrm{Ca}^{2+}$, the ability to exchange was increasingly smaller. When the SDBS was added into Ca-bent, $\mathrm{Na}^{+}$of SDBS exchange the $\mathrm{Ca}^{2+}$ of bentonite, but $\mathrm{C}_{18} \mathrm{H}_{29} \mathrm{O}_{3} \mathrm{~S}^{-}$was adsorbed on the surface of bentonite and inserted into the bentonite interlayer. The reaction process is as follows:

$$
\mathrm{Ca}-\mathrm{Bent}+2 \mathrm{Na}^{+} \rightarrow \mathrm{Na}_{2}-\mathrm{Bent}+\mathrm{Ca}^{2+}
$$

The single factor experiment and orthogonal experiment were used to study the process of modification. Firstly, under the condition of constant microwave parameters, the ratio of $\mathrm{Na}_{2} \mathrm{CO}_{3}$ to SDBS was changed. This experiment would fix the amount of sodium carbonate, and gradually increased the amount of SDBS then we change the ratio of $\mathrm{Na}_{2} \mathrm{CO}_{3}$ to SDBS. Then the ratio of SDBS to $\mathrm{Na}_{2} \mathrm{CO}_{3}$ was controlled in the best 
ratio in order to investigate the effect of microwave conditions on the modification. Finally, on the basis of single factor experiment, the orthogonal experiment of 3 levels and 4 factors were designed. Especially, in order to study the interaction between various factors, the select scope of orthogonal factors level in range of normal fluctuations of the influential factors in the single factor experiment. The fluctuation indicated the interaction of among the factors, so the interaction effect between all factors could be found by the orthogonal experiment.

\subsection{Measurement}

The modified bentonite and Na-based bentonite for drilling were measured according to API SPEC 13A-2010 Specification for Drilling Fluid Materials. [8] The test parameters included viscosity, swelling volume and $p H$, etc. The basic indicators of original Ca-Bent was showed in Table 1.

Table 1: The basic indicators of original Ca-Bent..

\begin{tabular}{l|l|l}
\hline NAME & DIMENSION & UNIT \\
\hline Type & Ca-Bent & \\
\hline Granularity & 325 & mesh \\
\hline $\mathrm{pH}$ & 6 & \\
\hline Swelling volume & 20 & $\mathrm{~mL} / \mathrm{g}$ \\
\hline Montmorillonite & $>85$ & $\%$ \\
\hline
\end{tabular}

The modified bentonite and Liaohe drilling grade bentonite were characterized by X-ray diffractometer and Fourier transform infrared spectrometer, the X-ray parameter was tube voltage $40 \mathrm{kV}$, current $40 \mathrm{~mA}$, wavelength 1.54056 , the 2-theta rage of $5-80^{\circ}$, and 001 planes were tested to obtain the distance between 001 layers. Besides Fourier transform infrared (FTIR) analyses were performed at room temperature in the spectral range of $4000-400 \mathrm{~cm}^{-1}$ using a FTIR spectrometer by $\mathrm{KBr}$ tabletting. Then the spectra were observed and analyzed.

\section{RESULTS AND DISCUSSION}

\subsection{Effect of the ratio of $\mathrm{Na}_{2} \mathrm{CO}_{3}$ to SDBS on modified bentonite}

In the preparation of modified agent, the work will fix the amount of sodium carbonate, and gradually increase the amount of SDBS, then the ratio of $\mathrm{Na}_{2} \mathrm{CO}_{3}$ to SDBS changed. It can be seen from Figure 1 that the swelling volume of bentonite increased gradually with the increase of SDBS. It is presumed that the $\mathrm{Na}_{2} \mathrm{CO}_{3}$ promoted the anionic surface activity of SDBS, so that the cation exchange was continuously shifted toward the positive. ${ }^{[9]}$ When the ratio of $\mathrm{Na}_{2} \mathrm{CO}_{3}$ to SDBS was 1:0.5, the swelling volume of bentonite reached the high value of $66 \mathrm{~mL} / \mathrm{g}$. Then the amount of SDBS increased, the swelling volume of bentonite decreased a little. It is probably that there will be notmore space for inhaled water molecule because sodium ions and organic ions have occupied the interlayer of bentonite, which results in the decrease of the swelling capacity. Finally, the optimum ratio of $\mathrm{Na}_{2} \mathrm{CO}_{3}$ to SDBS was chose as 1:0.5.

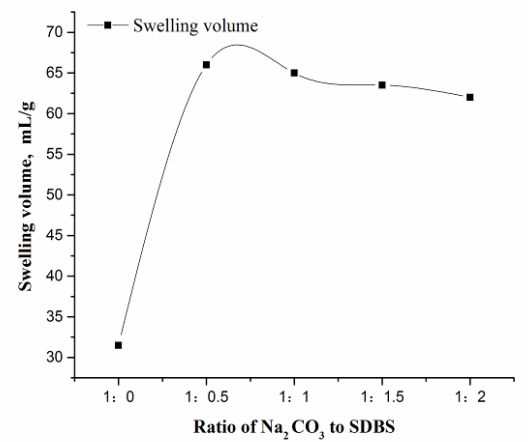

Figure 1: Effect of ratio of $\mathrm{Na}_{2} \mathrm{CO}_{3}$ to SDBS on sodium modification 


\subsection{Effect of microwave on Modified Bentonite}

In the process of microwave-assisted modified bentonite, the most critical parameters are microwave temperature, microwave irradiation time and microwave power. Meanwhile in the selective experiment of the parameters, the values of each parameter were selected according to the rated value of microwave apparatus.

It can be seen from Figure 2, when the initial modified temperature of microwave was $80 \mathrm{~K}$, the swelling volume of bentonite was $66 \mathrm{~mL} / \mathrm{g}$. It showed that the $\mathrm{Na}^{+}$in $\mathrm{Na}_{2} \mathrm{CO}_{3}$ can exchange with $\mathrm{Ca}^{2+}$ in bentonite. With the increase of temperature, the swelling volume of bentonite slightly increased. When the temperature reached $140 \mathrm{~K}$, swelling volume of bentonite had a maximum value $69 \mathrm{~mL} / \mathrm{g}$. Subsequently, with the increase of temperature, the swelling volume of bentonite slowly declined. It is proposed that. When the initial temperature was up to $180 \mathrm{~K}$, the experiment failed.[10]

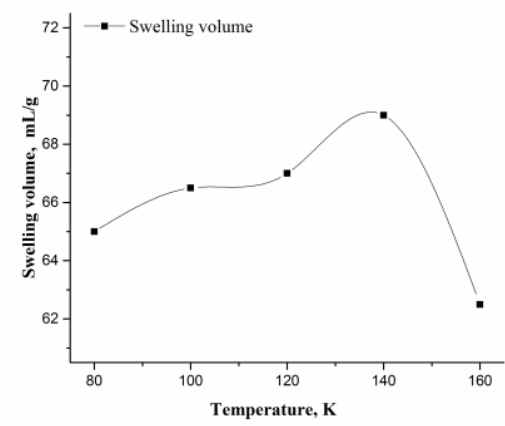

Figure 2: Effect of microwave temperature on sodium modification

As can be seen from Figure 3, With the increase of power, the swelling volume of bentonite suddenly increase, then when the microwave power was $500 \mathrm{~W}$, the maximum swelling volume is $68 \mathrm{~mL} / \mathrm{g}$. Then the swelling volume of bentonite abruptly decreased, ultimately the swelling volume of bentonite slightly decreased. This phenomenon may be because the main function of microwave radiation that eliminate effect of in-diffusion on sodium-modification process. Within a certain range of microwave radiation intensity, the indiffusion have been eliminated, the influencing factors of reaction occupies the dominant position. Therefore, unit mass of Ca-Bent was modified, it needs to microwave power about $80 \mathrm{~W} / \mathrm{g}$.

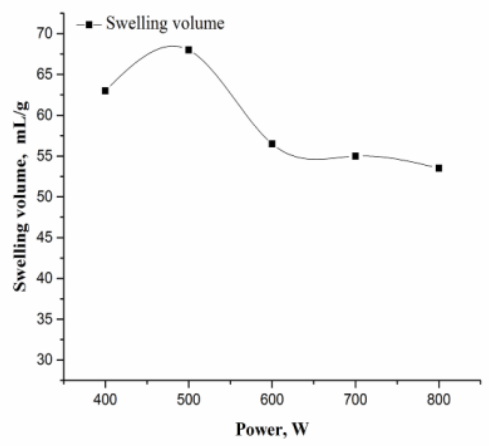

Figure 3: Effect of microwave radiation power on sodium modification

As can be seen from Figure 4. At first, the curve showed a slow upward trend, and then the rate of rise suddenly accelerated, when the microwave time was $3 \mathrm{~min}$, the maximum capacity was $65 \mathrm{~mL} / \mathrm{g}$, afterwards the curve suddenly dropped, the downtrend is slow at length. It is probably that the surface was modified at the beginning of the process, With the increase of time, temperature of reaction sharply increased, which lead to strong molecular thermal motion. If the time continue to extend, ion exchange equilibrium reaction will be breached. 


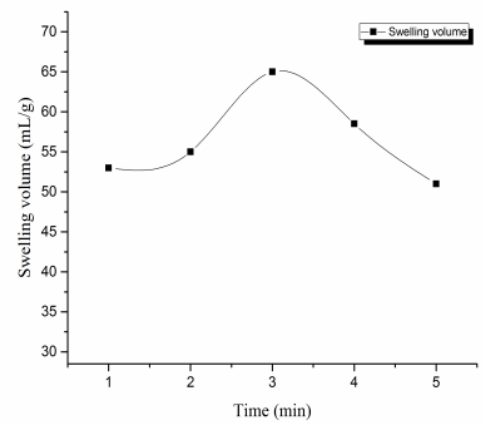

Figure 4: Effect of microwave irradiation time on sodium modification

\subsection{Orthogonal experiment}

Some factors were studied by single factor experiment, and then orthogonal experiments were carried out. The experimental factors were shown in Table 2, and the results were shown in Table 3.

Table 2: Experimental factor table

\begin{tabular}{c|c|c|c|c}
\hline FACTOR & PROPORTION & TIME/min & TEMPERATURE/K & POWER/W \\
& A & B & C & D \\
\hline 1 & $1: 0.5$ & 1 & 100 & 500 \\
\hline 2 & $1: 1$ & 2 & 120 & 600 \\
\hline 3 & $1: 1.5$ & 3 & 140 & 700 \\
\hline
\end{tabular}

Table 3: Data for orthogonal test

\begin{tabular}{|c|c|c|c|c|c|c|}
\hline NUMBER & $\mathbf{A}$ & B & C & D & $\begin{array}{c}\text { SWELLING } \\
\text { VOLUME } \\
\mathrm{mL} / \mathrm{g}\end{array}$ & $\begin{array}{c}\text { CEC } \\
\mathrm{mmol} / 10^{2} \mathrm{~g}\end{array}$ \\
\hline 1 & 1 & 1 & 1 & 1 & 61 & 50.7 \\
\hline 2 & 1 & 2 & 2 & 2 & 67.5 & 58.7 \\
\hline 3 & 1 & 3 & 3 & 3 & 65 & 20 \\
\hline 4 & 2 & 1 & 2 & 3 & 68 & 53.3 \\
\hline 5 & 2 & 2 & 3 & 1 & 69 & 36 \\
\hline 6 & 2 & 3 & 1 & 2 & 69.5 & 40 \\
\hline 7 & 3 & 1 & 3 & 2 & 18 & 32 \\
\hline 8 & 3 & 2 & 1 & 3 & 20.5 & 26.7 \\
\hline 9 & 3 & 3 & 2 & 1 & 22 & 37.3 \\
\hline $\mathrm{K}_{1}$ & 193.5 & 147 & 151 & 152 & & \\
\hline $\mathrm{K}_{2}$ & 206.5 & 157 & 157.5 & 155 & & \\
\hline $\mathrm{K}_{3}$ & 60.5 & 156.5 & 152 & 153.5 & & \\
\hline $\mathrm{R}$ & 146 & 10 & 6.5 & 3 & & \\
\hline
\end{tabular}




\begin{tabular}{c|c|c|c|c|l|l}
\hline $\mathrm{K}_{1}$ & 12.94 & 13.6 & 11.74 & 12.04 & & \\
\hline $\mathrm{K}_{2}{ }^{`}$ & 12.93 & 12.14 & 14.93 & 13.07 & & \\
\hline $\mathrm{K}_{3} \mathrm{R}^{`}$ & 9.6 & 9.73 & 8.8 & 10 & & \\
\hline $\mathrm{R}^{`}$ & 3.34 & 3.87 & 6.13 & 3.07 & & \\
\hline
\end{tabular}

There, CEC was cationic exchange capacity; $\mathrm{K}_{\mathrm{i}}$ was sum of the same level; $\mathrm{R}$ represented range of swelling volume; $\mathrm{K}_{\mathrm{i}}$ ' was was sum of the same level of CEC; $\mathrm{R}^{`}$ represented range of CEC.

As shown in Table 3, the main influencing factors of sodium-modification bentonite are the ratio of $\mathrm{Na}_{2} \mathrm{CO}_{3}$ to SDBS $(A>B>C>D)$ and temperature. The best modification condition was $\mathrm{A}_{2} \mathrm{~B}_{2} \mathrm{C}_{2} \mathrm{D}_{2}$, that is, the optimized experimental parameters are obtained as follows: $\mathrm{Na}_{2} \mathrm{CO}_{3}$ to SDBS ratio of 1:1, radiation time of 2 $\mathrm{min}$, microwave power of $600 \mathrm{~W}$ and initial temperature of $120 \mathrm{~K}$.

\subsection{Measure analysis}

The $p H$, swelling volume, yield point and plastic viscosity ratio of Na-based bentonite is $8,46 \mathrm{~mL} / \mathrm{g}$ and 0.8 , respectively. Under the optimization conditions, the modified bentonite has a swelling volume of $68.5 \mathrm{~mL} / \mathrm{g}$, $p H$ of 9 and yield point and plastic viscosity ratio of 1.67, respectively. Thus, it can be seen, the modified bentonite has well expansibility and rheological, and it is substantial foundation for later organic modification, because under the condition of weak alkali, Na-Bent was effectively modified with organics.

\subsection{Characterization of bentonite and its mechanism}

\subsubsection{IR spectra}

As shown in Figure 5, the characteristic absorption peaks were showed in the IR spectra of the original CaBent: a broad and strong -OH stretching vibration peak in $3650 \mathrm{~cm}^{-1} \sim 3600 \mathrm{~cm}^{-1}$, and the -OH stretching vibration peak near $1640 \mathrm{~cm}^{-1}$, both of them are the representation of crystalline water in bentonite lattice. And the modified bentonite by $\mathrm{Na}_{2} \mathrm{CO}_{3}$ and original Ca-Bent have associating -OH absorption peak in $3440 \mathrm{~cm}^{-1}$ and $3471 \mathrm{~cm}^{-1}$, it is sign of absorbed water in bentonite layer, but the absorption peak disappeared on spectra of composite modified bentonite. According to the IR spectra of modified bentonite by SDBS- $\mathrm{Na}_{2} \mathrm{CO}_{3}$ compared with modified bentonite by $\mathrm{Na}_{2} \mathrm{CO}_{3}$, a pronounced $\mathrm{C}-\mathrm{H}$ asymmetric stretching vibration and symmetric stretching vibration peaks in the $2950 \mathrm{~cm}^{-1} \sim 2830 \mathrm{~cm}^{-1}$ are present to the IR spectra, furthermore the peak belongs to SDBS. What's more, there is the strong absorption band of Si-O near $1030 \mathrm{~cm}^{-1}$, and it has bending vibration peaks of Al-O and Si-O in $400 \mathrm{~cm}^{-1} \sim 600 \mathrm{~cm}^{-1}$. In summary, the rest of modified bentonite spectrum and Ca-Bent spectrum are similar, but there are also differences, which also shows that the structure of three different substance, these positions of absorption peak indicate that SDBS entered into the layers of bentonite, it was successful intercalation.[11]
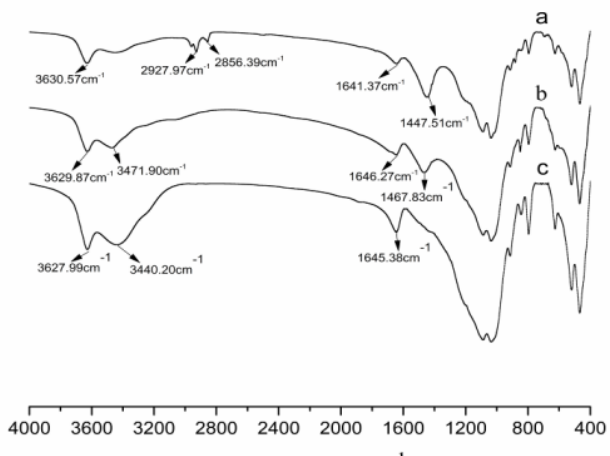

Wavenumber, $\mathbf{~ c m}^{-1}$

Figure 5: IR spectra of the modified bentonite by SDBS- $\mathrm{Na}_{2} \mathrm{CO}_{3}$ (spectrum a), the modified bentonite by $\mathrm{Na}_{2} \mathrm{CO}_{3}$ (spectrum b) and unmodified bentonite (spectrum c). 


\subsubsection{X-Ray diffraction}

The results of characterization by XRD of unmodified Ca-Bent and modified Ca-Bent are presented in Figure. 6. SDBS and $\mathrm{Na}_{2} \mathrm{CO}_{3}$ not only modified raw bentonite, but also smoothed surface of bentonite. There is a certain distance between the bentonite cell, which is generally called the layer spacing, and the 001-surface spacing is represented by $d_{001}$. When $2 \theta=5.729^{\circ}, d_{001}$ of unmodified bentonite is $1.53 \mathrm{~nm}$, when $2 \theta=7.061^{\circ}$, $d_{001}$ of modified bentonite is $1.25 \mathrm{~nm}$. By the modified bentonite compared with those of the unmodified bentonite, the intensities of diffraction peaks were significantly decreased, Because the constitutional water of interlayer is lost, and the layer structure was slightly recombined under the microwave radiation. Moreover, the $\mathrm{Na}^{+}$radius is small, it can only adsorb water molecules of a layer while $\mathrm{Ca}^{2+}$ absorb water molecules of two layers, so the modified bentonite layer spacing is smaller, it illustrates that $\mathrm{Na}^{+}$has exchanged $\mathrm{Ca}^{+}$in $\mathrm{Ca}$ Bent. Besides, the crystallinity of modified bentonite becomes significantly worse, but its activity, purity and colloidal properties are enhanced, because SDBS promoted ion exchange between $\mathrm{Na}_{2} \mathrm{CO}_{3}$ and Ca-Bent.[12]

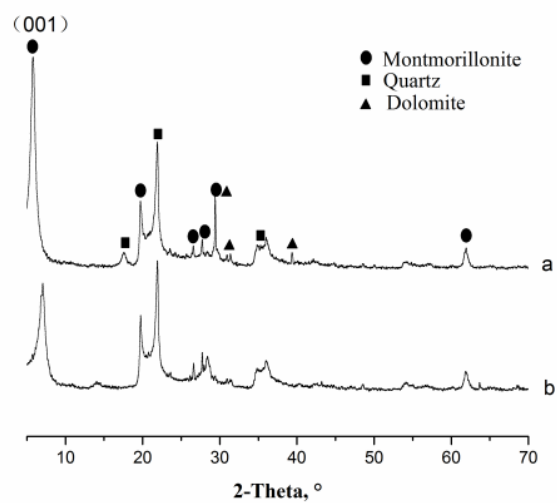

Figure 6: XRD patterns of unmodified bentonite(a) and modified bentonite(b)

\section{CONCLUSIONS}

In this work, $\mathrm{Ca}-\mathrm{Bent}$ was modified with $\mathrm{SDBS}$ and $\mathrm{Na}_{2} \mathrm{CO}_{3}$ by microwave. The chemical bonds, phase constitution and morphology of the unmodified and modified Ca-Bent were studied by FTIR and XRD, respectively. It was found that the ratio of $\mathrm{Na}_{2} \mathrm{CO}_{3}$ to SDBS, initial temperature and radiation time and microwave power had influences on the modification process of bentonite. And SDBS and $\mathrm{Na}_{2} \mathrm{CO}_{3}$ modified Ca-Bent by microwave, which made synchronization between sodium-modification and organic-modification, besides, it obtained a high swilling bentonite of $68.5 \mathrm{~mL} / \mathrm{g}$. SDBS and $\mathrm{Na}_{2} \mathrm{CO}_{3}$ have synergistic effect in the process of modified bentonite, and $\mathrm{Na}_{2} \mathrm{CO}_{3}$ increased the anion surface activity of SDBS, which enhanced the hydrophilicity of modified bentonite, besides, SDBS promoted ion exchange between $\mathrm{Na}_{2} \mathrm{CO}_{3}$ and Ca-Bent. So, The modified bentonite has superduper rheology, activity and colloidality than modified bentonite by single inorganic sodium salt. Particularly, the $\mathrm{Na}_{2} \mathrm{CO}_{3} / \mathrm{SDBS}$-bentonite was a novel high swelling bentonite, and it would be applied in water based drilling fluid.

\section{ACKNOWLEDGEMENTS}

This work was financially supported by 2017 Liaoning doctoral research foundation program (20170520344)," Preparation and Application of Clean Nanometer Bentonite Composite in Drilling Fluid". and the Opening Project of Guangxi Colleges and Universities Key Laboratory of Beibu Gulf Oil and Natural Gas Resource Effective Utilization(2016KLOG09).

\section{BIBLIOGRAPHY}

[1] CEYDA, B., DEMET, T.Y, NAILE, K., et al., "Surface and interface physicochemical aspects of intercalated organo-bentonite", International Journal of Adhesion \& Adhesives, v. 50, pp. 204-210, 2014.

[2] LEITE, I.F., RAPOSO, C.M.O., CARVALHO, L.H., et al., "Efeitos de Diferentes Argilas Organofílicas nas Propriedades de Compósitos PET/Bentonita", Matéria, v. 11, pp. 260-266, 2006.

[3] HUANG, W., ZHONG, Y., HAN G., et al., "Sodium-modification of Ca-based bentonite via semidry process", Journal of Central South University, v. 17, pp. 1201-1206, 2010.

[4] KUMARARAJA, P., MANJAIAH, K.M., DATTA, S.C., et al. "Remediation of metal contaminated soil 
by aluminium pillared bentonite: synthesis, characterisation, equilibrium study and plant growth experiment", Applied Clay Science, v. 137, pp. 115-122, 2017.

[5] ZHOU, C., FAN, X., NING, Z., et al. "Reducing riverbed infiltration using mixtures of sodium bentonite and clay", Environment Earth Science, v. 74, pp. 3089-3098, 2015.

[6] ABDOU, M.I., Al-SABAGH, A.M., DAIDIR, M.M., "Evaluation of Egyptian bentonite and nanobentonite as drilling mud", Egyptian Journal of Petroleum, v. 22, pp. 53-59, 2013.

[7] LI, S., YANG, S., ZHAO, S., et al. "Microwave and acid-modified talc for the adsorption of Methylene Blue in aqueous solution", Journal of the Serbian Chemical Society, v. 80, pp. 563-574, 2015.

[8] API SPEC 13A: Specification for Drilling Fluid Materials (2010).

[9] KHIMANI, M., VORA, S., "Effect of inorganic additives on a conventional anionic-nonionic mixed surfactants system in aqueous solution", Journal of Surfactants and Detergents, v. 14, pp. 545-554, 2011.

[10] LUAN, D.L., TANG, J.M., LIU, F., et al., "Dielectric properties of bentonite water pastes used for stable loads in microwave thermal processing systems", Journal of Food Engineering, v. 161, pp. 40-47, 2015.

[11] LI, Y., JIN, F.L., CHEN, X.Y., WANG, C., et al., "Modification of bentonite with cationic surfactant for the enhanced retention of bisphenol A from landfill leachate", Environmental Science and Pollution Research, v. 22, pp. 8618-8628, 2015.

[12] ANDRINI, I, TOJA, M.R., GAUNA, M.R., et al., "Extended and local structural characterization of a natural and $800^{\circ} \mathrm{C}$ fired Na-montmorillonite-Patagonian bentonite by XRD and Al/Si XANES", Applied Clay Science, v. 137, pp. 233-240, 2017. 